Manuelle Medizin 2021 · 59:283

https://doi.org/10.1007/s00337-021-00835-1

Published online: 5 October 2021

(c) The Author(s) 2021

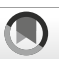

Check for
updates

\section{Erratum to: Forced posture of neurology residents in daily routine on the ward in Germany}

\author{
A pilot study
}

\author{
Anne Bijanzadeh' · Ingo Hermanns ${ }^{2} \cdot$ Rolf Ellegast $^{2}$. Laura Fraeulin ${ }^{1}$. \\ Fabian Holzgreve ${ }^{1}$. David A. Groneberg ${ }^{1}$ - Daniela Ohlendorf ${ }^{1}$ \\ 'Institute for Occupational Medicine, Social Medicine and Environmental Medicine, Goethe-University \\ Frankfurt, Frankfurt am Main, Germany \\ ${ }^{2}$ Institute for Occupational Health and Safety (IFA), German Social Accident Insurance (DGUV), Sankt \\ Augustin, Germany
}

The online version of the original article can be found under https://doi.org/10.1007/s00337021-00819-1.

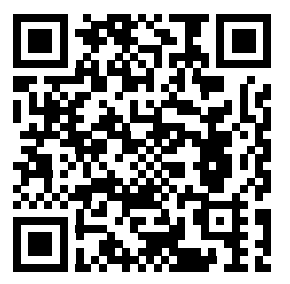

Scan QR code \& read article online

\section{Erratum to:}

Manuelle Medizin 2021

https://doi.org/10.1007/s00337-021-

00819-1

The original online version of this article unfortunately contained some mistakes.

- The order of the authors in the author list was incorrect. As the order has been corrected, the article note regarding first and last author has become redundant and has been removed.

- Fig. 1 and its reference in the text have been removed and the subsequent figures and their references have been renumbered accordingly.

- Reference [20] whose details are given below has been added to the reference list and the subsequent entries in the reference list have been renumbered.

- In the first section of the article, the sentence "In this context, the CUELA system has already been used successfully in several studies $[2,18$, 19]." has been extended to include the information "and is part of the MAGROMSA project [20]"

- In the "Materials and methods" section, the following first sentence has been added at the beginning of the subsection "Subjects": "This study is part of the MAGRO-MSA project that focuses on neurologists which has already been published in part earlier $[14,20] .$.
The original article has been corrected.

Corresponding address

PD Dr. Dr. Daniela Ohlendorf Institute for Occupational Medicine, Social Medicine and Environmental Medicine, Goethe-University Frankfurt Theodor-Stern-Kai 7, House 9b, 60590 Frankfurt am Main, Germany

ohlendorf@med.uni-frankfurt.de

Open Access. This article is licensed under a Creative Commons Attribution 4.0 International License, which permits use, sharing, adaptation, distribution and reproduction in any medium or format, as long as you give appropriate credit to the original author(s) and the source, provide a link to the Creative Commons licence, and indicate if changes were made. The images or other third party material in this article are included in the article's Creative Commons licence, unless indicated otherwise in a credit line to the material. If material is not included in the article's Creative Commons licence and your intended use is not permitted by statutory regulation or exceeds the permitted use, you will need to obtain permission directly from the copyright holder. To view a copy of this licence, visit http://creativecommons.org/licenses/by/4.0/.

\section{References}

20. Ohlendorf D, Schwarzer M, Rey J, Hermanns I, Nienhaus A, Ellegast R, Ditchen D, Mache $S$, Groneberg DA (2015) Medical work assessment in German hospitals: a study protocol of a movement sequence analysis (MAGRO-MSA). J Occup Med Toxicol 10(1):1. https://doi.org/10.1186/s12995014-0040-7 